\title{
PALHAÇOTERAPIA COMO FERRAMENTA DE EDUCAÇÃO EM SAÚDE ACERCA DA HANSENÍASE: RELATO DE EXPERIÊNCIA
}

\section{Elivelton Sousa Montelo후 Amanda Azevedo Torres²; Alexia Jade Machado Sousa ${ }^{3}$; Andréia Ferreira dos Santos' ${ }^{4}$ Maria Samara Da Silva'; Amanda Célis Brandão Vieira ${ }^{6}$; Eneida Anjos Paiva $^{7}$}

${ }^{1}$ Acadêmico de Fisioterapia, Universidade Federal do Delta do Parnaíba (UFDPar), Parnaíba, Piauí. ${ }^{2}$ Acadêmica de Medicina, Universidade Federal do Delta do Parnaíba (UFDPar), Parnaíba, Piauí.

${ }^{3}$ Acadêmica de Psicologia, Universidade Federal do Delta do Parnaíba (UFDPar), Parnaíba, Piauí. ${ }^{4}$ Acadêmica de Medicina, Universidade Federal do Delta do Parnaíba (UFDPar), Parnaíba, Piauí. ${ }^{5}$ Pós Graduanda em Fisioterapia na Saúde da Mulher, Aprimore, Teresina, Piauí. ${ }^{6}$ Pós Graduanda em Fisioterapia na Saúde da Mulher, Inspirar, Teresina, Piauí. ${ }^{7}$ Prof ${ }^{a}$ do curso de Medicina, Universidade Federal do Delta do Parnaíba (UFDPar), Parnaíba, Piauí. DOI: $10.47094 /$ ICONRES.2021/4

\begin{abstract}
RESUMO
Introdução: Hanseníase é uma doença crônica que pode ser transmitida por fluidos orais. Diversos fatores atrasam o diagnóstico, como: busca tardia de atendimento e falta de informação sobre sintomatologia. A educação em saúde são práticas que buscam promoção e prevenção de saúde nos diversos níveis de complexidade. A palhaçoterapia busca melhorar a situação psicológica de populações vulneráveis, contribuindo para um cuidado multidisciplinar, tendo a alegria como instrumento e o palhaço como intérprete. Objetivo: Relatar a experiência de uma prática de educação em saúde sobre hanseníase, utilizando a palhaçoterapia. Método: relato de uma experiência realizada em Parnaíba-PI. A prática utilizou-se da palhaçoterapia para educar sobre hanseníase. Resultados e discussão: Os diálogos remetiam às dúvidas sobre fisiopatologia, transmissão, sintomatologia e histórico. Conclusão: A palhaçoterapia é uma potente ferramenta de educação em saúde, sobretudo, pelo impacto positivo do humor e da ludicidade em captar atenção dos ouvintes e pelo estado de bemestar provocado.
\end{abstract}


PALAVRAS-CHAVES: Doenças Negligenciadas; Humor; Humanização dos Serviços.

ÁREA TEMÁTICA: Educação em Saúde

\section{INTRODUÇÃO}

Define-se hanseníase como uma doença infectocontagiosa de evolução crônica, causada pela bactéria Mycobacterium leprae, de baixa patogenicidade e alta infectividade e que acomete os nervos periféricos e pele, podendo ser transmitida por meio de fluidos orais (NASCIMENTO C et al., 2019). Segundo a Organização Mundial da Saúde (OMS) o Brasil é o segundo país mais acometido pela patogenia, com $12,5 \%$ de casos registrados no mundo. A apesar da diminuição dos casos a cada ano, o país ainda não atingiu a meta de eliminação da doença, o que faz ainda desse cenário um problema de saúde pública (FREITAS BHBM et al., 2019).

Ademais, diversos fatores contribuem para o atraso no diagnóstico da doença, entre eles, pontua-se: a busca tardia de atendimento nos serviços de saúde, a falta de informação da população sobre sinais e sintomas, a dificuldade dos indivíduos em encontrar serviços especializados de saúde para detecção e tratamento da doença. Diante disso, apresenta-se como ferramenta para enfrentamento da hanseníase a Vigilância em Saúde, com execução de práticas de saúde adequadas, que garantam não só a detecção e o tratamento da doença, mas também a educação em saúde (COSTA AKAN, et al., 2018).

Entende-se como educação em saúde um campo de conhecimento e de práticas que buscam promoção e prevenção de saúde nos diversos níveis de complexidade do processo adoecimento em todo o ciclo de vida humana. Assim, é compreendida como o processo de aprendizagem teórico-prático que possui o objetivo de integrar diversos saberes, como o científico, o popular e o do senso comum, possibilitando que os indivíduos envolvidos desenvolvam uma visão crítica acerca da produção do cuidado e autocuidado em saúde (RAMOS CFV, et al., 2018)

A educação em saúde consiste em uma das ações mais importantes dos serviços de atenção primária a saúde (APS), podendo ser executada por todos os profissionais de saúde, independente do cargo exercido nestas instituições (RIBEIRO KG, et al. 2018). Diante dessa premissa multiprofissional, no âmbito da APS, são os agentes comunitários de saúde (ACS) que possuem a função de serem pontes de conhecimentos do universo cientifico para o popular, sendo assim importantes facilitadores do acesso da população aos cuidados de saúde, aumentando o alcance da educação em saúde como instrumento modificador de posturas e hábitos (MIALHE FL, et al., 2018).

Nessa perspectiva, a educação em saúde se fundamenta de acordo com a Política Nacional de Humanização (HumanizaSUS) que define humanização como estratégia de interferência no processo de produção de saúde, levando-se em conta que sujeitos sociais, quando mobilizados, são capazes de transformar realidades, transformando a si próprios nesse mesmo processo. Dessa forma, entende-se que as práticas de saúde devem propiciar aos pacientes ferramentas que vão além da prática clínica e 
do modelo biomédico (BRASIL, 2004).

Em linha com a HumanizaSUS, métodos como a palhaçoterapia têm por finalidade melhorar a situação psicológica de populações em risco, e atuar como promotores de saúde, contribuir para um cuidado inter e multidisciplinar, construir espaço onde os profissionais possam dar liberdade para expor a sua criatividade, estimular a manifestação da imaginação dos ouvintes e o desenvolvimento de sua autonomia, além de encurtar os espaços entre os diversos atores dos ambientes de saúde, tendo a alegria como instrumento e o palhaço como intérprete (MARINHO ADM, 2015). Com isso, o objetivo desse trabalho é relatar a experiência de uma prática de educação em saúde sobre hanseníase, utilizando a palhaçoterapia, organizada por ACS de Parnaíba - PI e por participantes do PET-Saúde/ Interprofissionalidade.

\section{METODOLOGIA}

Trata-se de um estudo descritivo do tipo relato de experiência. A atividade foi realizada em novembro de 2019 no Hospital Colônia do Carpina (HCC), no bairro Frei Higino em Parnaíba-PI. A prática de educação em saúde proposta foi executada pelo grupo Teatro dos Agentes Comunitários de Saúde (TACS), utilizando-se da figura do Clown em sua performance para repassar informações acerca da hanseníase. A plateia presente era composta por funcionários e moradores do HCC, equipes da APS de Parnaíba-PI, integrantes da Vigilância Epidemiológica (representando a gestão municipal), a população adscrita do território, os participantes do Movimento de Reintegração da Pessoa com Hanseníase (MORHAN), e, como organizadores do encontro, os integrantes do PETSaúde/Interprofissionalidade.

\section{RESULTADOS E DISCUSSÃO}

A ação de palhaçoterapia desenvolvida pelo grupo TACS foi o marco inicial de uma sequência de atividades que visava compreender a linha de cuidado e prevenção relacionada à hanseníase em Parnaíba-PI, além de promover uma articulação entre os atores institucionais e sociais ali presente. A apresentação iniciou às $9 \mathrm{~h}$ da manhã, ao ar livre, no ambiente externo do HCC, o grupo de palhaços entrou em cena, a caráter, portando instrumentos musicais e entoando canções autorais do grupo.

Logo após, deu início às cenas com diálogos entre os personagens que remetiam às dúvidas, estigmas e informações usualmente distorcidas sobre a hanseníase. Nesse momento, o grupo promoveu educação em saúde ao dinamizar o conhecimento científico sobre a fisiopatologia, cadeia de transmissão, sinais e sintomas, estigmas sobre a doença e um pouco sobre o HCC no contexto histórico do processo de isolamento compulsório dos atingidos pela hanseníase. O espetáculo prendeu a atenção do público enquanto promovia risadas dos presentes, utilizando-se de piadas bem colocadas, com um humor limpo e informações pertinentes, o tema hanseníase foi tratado com muita delicadeza e esclarecimento. 
Assim, a ação cumpriu com o que é preconizado na humanização no contexto da saúde, com a inserção de grupos que envolvam vários sujeitos e setores na modificação da cultura institucional do modelo biomédico, tornando-a mais humanizada (SILVA CPR, et al., 2017). Nesse cenário, pontuase que entre os sujeitos presentes, estavam os moradores do HCC e usuários do próprio território e territórios vizinhos, essa participação ressalta a importância de tais ações educativas e o protagonismo da comunidade nas práticas de educação em saúde, empoderando-a em relação ao autocuidado e a fim de quebrar paradigmas sobre a doença (ARAÚJO AP, 2017).

Como ferramenta para a educação em saúde, a palhaçoterapia visa fazer a ponte entre o cuidar eficiente a um cuidar mais humano, de acordo com a definição ampliada da saúde, que considera o ser humano como um todo em suas multiplicidades, para além do corpo físico. A centralidade deixa de ser a doença, o doente ou seus sintomas físicos e passa a ser a pessoa, sua nova realidade institucionalizada e os sentimentos consequentes dessas alterações (CATAPAN SC, 2017). Ademais, tendo em vista a participação e as boas risadas dos pacientes do HCC, ressalta-se a importância do humor ou terapia clown como uma alternativa lúdica para idosos institucionalizados, proporcionando alegria, descontração, ao mesmo tempo em que auxilia na manutenção da saúde e qualidade de vida (PIRES WGB, et al., 2015).

Segundo Silva e Paz (2010), para os profissionais da saúde, a educação em saúde é uma atividade primordial centrada na transmissão de informações, tanto aos portadores de hanseníase, como também à população como um todo. A participação dos usuários dos serviços durante atividades educativas é essencial, pois se tornam espaços de esclarecimento. A partir disso, quanto mais informação, melhor será o enfrentamento da doença.

Além disso, é necessário que os profissionais instruam os portadores da doença e a população em geral sobre o problema da hanseníase, sendo responsáveis por melhorar o conhecimento da população, não apenas dos que estão em tratamento, mas também daqueles que convivem com os portadores. Se inteirar e compreender as atividades educativas como fundamentais ao processo terapêutico no plano individual (SILVA MCD, PAZ EPA, 2010). Ainda é possível se observar grande carga de estigma e preconceito quanto à hanseníase, o que dificulta a execução de medidas de controle e também de profilaxia. Desse modo, a educação em saúde se mostra como um instrumento necessário para o esclarecimento de suas consequências e suas formas de prevenção (COROLIANO-MARINUS, 2012 citado em MOREIRA AJ et al., 2014).

\section{CONCLUSÃO}

Portanto, conclui-se que a palhaçoterapia é uma potente ferramenta quando usada em ações de educação em saúde, sobretudo, pelo impacto positivo do humor e da ludicidade em captar atenção dos ouvintes e pelo bem-estar provocado pelo riso. Nota-se também a importância de ações educativas, como essa, baseadas nas diretrizes do HumanizaSUS, sobre doenças negligenciadas como a hanseníase, afim de promover auto cuidado e autonomia de conhecimento quanto à prevenção e a 
quebra de paradigmas que envolve o histórico de estigmas sobre a doença.

\section{PRINCIPAIS REFERÊNCIAS}

DE SOUZA, Ronimara Gonçalves; LANZA, Fernanda Moura; SOUZA, Raissa Silva.

Sensibilização dos Agentes Comunitários de Saúde para a atuação nas ações prevenção e controle da hanseníase: relato de experiência. HU Revista, v. 44, n. 3, p. 411-415, 2018.

FREITAS, Bruna Hinnah Borges Martins de et al. Práticas educativas sobre laenfermedad de Hansen (Lepra) con adolescentes: revisión integrativa de la literatura. Revista Brasileira de Enfermagem, v. 72, n. 5, p. 1397-1404, 2019.

NASCIMENTO COSTA, Ana Karla Araújo et al. ASPECTOS CLÍNICOS E EPIDEMIOLÓGICOS DA HANSENÍASE. Journal of Nursing UFPE/Revista de Enfermagem UFPE, v. 13, n. 2, 2019.

SILVA, Maria Cristina Dias; PAZ, Elisabete Pimenta Araújo. Educação em saúde no programa de controle da hanseníase: a vivência da equipe multiprofissional. Esc. Anna Nery, Rio de Janeiro, v. 14, n. 2, p. 223-229, June 2010. 